Journal of

Molecular Microbiology

\title{
Archaeal and Bacterial Community Structure in an Anaerobic Digestion Reactor (Lagoon Type) Used for Biogas Production at a Pig Farm
}

\author{
Liliana Pampillón-González ${ }^{a}$ Nadia L. Ortiz-Cornejo ${ }^{b}$ Marco Luna-Guido ${ }^{b}$ \\ Luc Dendooven $^{b}$ Yendi E. Navarro-Noya ${ }^{c}$ \\ ${ }^{a}$ División Académica de Ciencias Biológicas, Universidad Juárez Autónoma de Tabasco, Tabasco, and ${ }^{\text {b Laboratory }}$ \\ of Soil Ecology, ABACUS, Cinvestav, Mexico City, and ' Cátedras CONACYT - Universidad Autónoma de Tlaxcala, \\ Tlaxcala, Mexico
}

\section{Keywords}

Acetoclastic methanogenesis · Anaerobic digestion . Biogas production - Hydrogenotrophic methanogenesis . Syntrophic bacteria $\cdot 16 \mathrm{~S}$ metagenomics

\begin{abstract}
Biogas production from animal waste is an economically viable way to reduce environmental pollution and produce valuable products, i.e., methane and a nutrient-rich organic waste product. An anaerobic digestion reactor for biogas production from pig waste was sampled at the entrance, middle (digestion chamber), and exit of a digester, while the bacterial and archaeal community structure was studied by $16 \mathrm{~S}$ rRNA gene metagenomics. The number of bacterial operational taxonomic units (OTU)-97\% was 3-7 times larger than that of archaeal ones. Bacteria and Archaea found in feces of animals (e.g., Clostridiaceae, Lachnospiraceae, Ruminococcaceae, Methanosarcina, Methanolobus, Methanosaeta, and Methanospirillum) dominated the entrance of the digester. The digestion chamber was dominated by anaerobic sugar-fermenting OP9 bacteria and the syntrophic bacteria Candidatus Cloacamonas (Waste Water of Evry 1; WWE1). The methanogens dominant in the digestion cham-
\end{abstract}

\section{KARGER}

(C) 2017 S. Karger AG, Basel

E-Mail karger@karger.com

www.karger.com $/ \mathrm{mmb}$ ber were the acetoclastic Methanosaeta and the hydrogenothrophic Methanoculleus and Methanospirillum. Similar bacterial and archaeal groups that dominated in the middle of the digestion chamber were found in the waste that left the digester. Predicted functions associated with degradation of xenobiotic compounds were significantly different between the sampling locations. The microbial community found in an anaerobic digestion reactor loaded with pig manure contained microorganisms with biochemical capacities related to the 4 phases of methane production.

(c) 2017 S. Karger AG, Basel

\section{Introduction}

Farms dedicated to pork production have adopted anaerobic digestion of pig waste not only as a way to reduce the generated waste but mainly to produce biogas, i.e. methane $\left(\mathrm{CH}_{4}\right)$ [Thygesen et al., 2014]. Biogas production from animal waste is widely used in Denmark, France, Germany, Italy, the UK, and Spain. In Latin America, e.g., Mexico, the use of anaerobic digestion of animal waste and biogas production has only become substantial in recent years. One of the advantages of the

Yendi E. Navarro-Noya

Cátedras CONACYT - Centro Tlaxcala de Biología de la Conducta Universidad Autónoma de Tlaxcala, Carretera Federal Tlaxcala-Puebla km 1.5 Tlaxcala 90070 (Mexico)

E-Mail yenavarrono@ conacyt.mx 
produced biogas is that it has a wide range of applications, especially in the energy sector. For instance, biogas can be used in a hob or stove, in an internal combustion engine, for lighting, in heaters or in grain driers. Lorenz et al. [2013], for instance, stated that biogas could provide 5\% of the total energy needed in the German paper industry and up to $71.2 \%$ in the brewery industry. Additionally, the organic product that remains after anaerobic digestion can easily be applied to soil, as it is nutrient rich [Nkoa, 2014].

The organic material in animal waste is mostly easily decomposable, so a lot of microorganisms thrive in it. The microorganisms in animal waste are mostly anaerobic and thus ideally suited to decompose the organic material in an anaerobic digester and produce $\mathrm{CH}_{4}$, i.e., biogas [Moset et al., 2014]. Anaerobic digestion consists of synergistic and sequential processes done by bacterial and archaeal groups. The sequential metabolic steps are hydrolysis, acidogenesis, acetogenesis, and methanogenesis. Bacteria first degrade the complex and high-molecularweight organic compounds until generation of hydrogen and acetate, which are then used by archaeal microorganisms to produce $\mathrm{CH}_{4}$ and $\mathrm{CO}_{2}$ [Moset et al., 2014; Zinder and Koch, 1984]. Bacterial groups produce acetate by oxidation of fermentation products of formate or hydrogenproducing bacteria [Hattori et al., 2000]. Methane is produced by a specialized group of Archaea, i.e., methanogens [Xia et al., 2014]. Methane is produced mainly from acetate by acetoclastic or from $\mathrm{H}_{2} / \mathrm{CO}_{2}$ by hydrogenotrophic methanogenic Archaea. A coordinated and well-adjusted interaction between the microbial groups involved in each of the biochemical processes is crucial for the efficiency of biogas production in anaerobic reactors. Several factors, e.g., temperature, $\mathrm{pH}$, and organic material composition, affect biogas production during anaerobic digestion [Karakashev et al., 2006], and fluctuations in these variables can imbalance the synergistic processes.

It is of great practical interest to identify the microorganisms, i.e. Archaea and Bacteria, involved in the different phases of anaerobic digestion, to assess the impact they have on $\mathrm{CH}_{4}$ production and to relate their metabolic capacity to the physicochemical characteristics of the system so that biogas production can be optimized further. Therefore, an anaerobic digestion reactor sampled at 2 locations (the digester reactor and at the exit of the digester or sedimentation pond) was characterized and extracted for DNA. The mixing fossa or the entrance to the digester was also sampled and characterized as it determined the quality of the slurry before it was added to the reactor. The archaeal and bacterial community

Microbial Communities in a Biogas Reactor structure was investigated by metagenomics of the V1-V3 hypervariable regions of the $16 \mathrm{~S}$ rRNA gene and correlated with the physicochemical characteristics of the system. A functional profile (metagenome) was developed to relate the microbial taxonomic composition with potential metabolic functions.

\section{Results and Discussion}

\section{Characteristics of the Organic Pig Waste in the} Anaerobic Digestion Reactor

The number of total coliforms decreased in the following order: mixing fossa $\left(>1,100 \times 10^{3}\right.$ colony-forming units $[\mathrm{CFU}])>$ digester reactor $\left(93 \times 10^{3} \mathrm{CFU}\right)>$ sedimentation pond $\left(2.3 \times 10^{3} \mathrm{CFU}\right)$, while fecal coliforms decreased in the following order: digester reactor $(150 \times$ $\left.10^{3} \mathrm{CFU}\right)>$ mixing fossa $\left(110 \times 10^{3} \mathrm{CFU}\right)>$ sedimentation pond $\left(23 \times 10^{3} \mathrm{CFU}\right)$. The reduction in coliform bacteria in the digester reactor was expected as digestion under thermophilic conditions or with termophilic pretreatments has been proven to reduce the pathogen bacteria and intestinal parasites found in animal waste [El-Mashad et al., 2004].

The water content in the mixing fossa was $95.8 \%$, and it was $85.2 \%$ in the digester reactor and $95.0 \%$ in the sedimentation pond. The organic $\mathrm{C}$ and chemical oxygen demand were significantly higher in the mixing fossa than in the digester reactor and the sedimentation pond, while the $\mathrm{pH}$ followed an opposite pattern and increased $(p \leq$ 0.05 ; Table 1). The concentration of $\mathrm{NO}_{2}{ }^{-}$was significantly higher in the digester reactor than in the mixing fossa and the sedimentation pond $(p \leq 0.05)$. Electrolytic conductivity (EC), inorganic $\mathrm{C}$, total $\mathrm{N}$ and the concentration of $\mathrm{NH}_{4}{ }^{+}$and $\mathrm{NO}_{3}{ }^{-}$were not significantly different among the 3 locations. Chemical equilibrium is very important in the biogas production process, which will affect $\mathrm{CH}_{4}$ yields and biogas quality. $\mathrm{pH}$ increases in the digester reactor and the sedimentation pond might be correlated with inorganic $\mathrm{C}$ and organic $\mathrm{C}$ as $\mathrm{pH}$ is significantly affected by carbon dioxide $\left(\mathrm{CO}_{2}\right)$, volatile fatty acids, and alkalinity [Sun et al., 2016]. Alkalinity is an indicator of the buffering capacity of the anaerobic reactor, which is characteristic when livestock waste, such as swine manure (rich in $\mathrm{NH}_{4}{ }^{+}$and nitrogen compounds), is used [Manyi-Loh et al., 2013]. An elevated $\mathrm{NH}_{3} / \mathrm{NH}_{4}{ }^{+}$ concentration is also related to the buffering capacity that allows operation of the digester with higher concentrations of volatile fatty acids [Walker et al., 2011]. However, the $\mathrm{NH}_{3}$ concentration in our anaerobic digestion reactor

J Mol Microbiol Biotechnol 2017;27:306-317 DOI: $10.1159 / 000479108$ 
Table 1. Characteristics of samples taken at 3 locations in an anaerobic digester of pig waste on 3 consecutive occasions with approximately 50 days in between

\begin{tabular}{|c|c|c|c|c|c|c|c|c|c|}
\hline $\begin{array}{l}\text { Sampling } \\
\text { location }\end{array}$ & $\mathrm{pH}$ & $\mathrm{EC}, \mathrm{dS} \cdot \mathrm{m}^{-1}$ & Tot-C, mg. $\mathrm{L}^{-1}$ & Ino- $\mathrm{C}, \mathrm{mg} \cdot \mathrm{L}^{-1}$ & Total N, mg. $\mathrm{L}^{-1}$ & $\mathrm{COD}, \mathrm{mg} \cdot \mathrm{L}^{-1}$ & $\mathrm{NH}_{4}^{+}, \mathrm{mg} \cdot \mathrm{L}^{-1}$ & $\mathrm{NO}_{2}^{-}, \mathrm{mg} \cdot \mathrm{L}^{-1}$ & $\mathrm{NO}_{3}{ }^{-}, \mathrm{mg} \cdot \mathrm{L}^{-1}$ \\
\hline Mixing fossa & $7.0 \pm 0.01^{\mathrm{b}}$ & $13.3 \pm 0.78^{\mathrm{a}}$ & $2,464.6 \pm 10.87^{\mathrm{a}}$ & $542.1 \pm 152.57^{\mathrm{a}}$ & $725.8 \pm 129.23^{\mathrm{a}}$ & $52,281.93 \pm 4875.50^{\mathrm{a}}$ & $142^{\mathrm{a}}$ & $0.41 \pm 0.07^{\mathrm{b}}$ & $0.36 \pm 0.03^{\mathrm{a}}$ \\
\hline Digester & $7.5 \pm 0.35^{\mathrm{a}, \mathrm{b}}$ & $14.0 \pm 0.96^{\mathrm{a}}$ & $1,561.8 \pm 279.14^{\mathrm{b}}$ & $641.3 \pm 148.93^{\mathrm{a}}$ & $648.3 \pm 77.10^{\mathrm{a}}$ & $31,189.48 \pm 3581.69^{b}$ & $163^{\mathrm{a}}$ & $0.80 \pm 0.01^{\mathrm{a}}$ & $0.36 \pm 0.07^{\mathrm{a}}$ \\
\hline Lagoon & $8.2 \pm 0.39^{\mathrm{a}}$ & $14.7 \pm 0.70^{\mathrm{a}}$ & $1,208.7 \pm 224.20^{\mathrm{b}}$ & $641.48 \pm 182.11^{\mathrm{a}}$ & $758.03 \pm 49.26^{\mathrm{a}}$ & $10,417.90 \pm 4194.69^{c}$ & $153^{\mathrm{a}}$ & $0.35 \pm 0.06^{\mathrm{b}}$ & $0.35 \pm 0.12^{\mathrm{a}}$ \\
\hline MSD & 0.9 & 2.5 & 635 & 1583 & 280 & 13,040 & 77 & 0.17 & 0.25 \\
\hline$F$ value & 7.92 & 1.57 & 19.62 & 1.09 & 0.76 & 48.51 & 0.35 & 39.17 & 0.01 \\
\hline$p$ value & 0.021 & 0.283 & 0.002 & 0.394 & 0.508 & $<0.001$ & 0.719 & $<0.001$ & 0.990 \\
\hline
\end{tabular}

EC, electrolytic conductivity; Tot-C, total carbon; Ino-C, inorganic carbon; COD, chemical oxygen demand; MSD, minimum significant difference ( $p<0.05$ ).

remained constant, although it generally increases. Some $\mathrm{NH}_{3}$ might get lost through volatilization, as the $\mathrm{pH}$ in the anaerobic reactor is alkaline [Strik et al., 2006].

\section{Alpha Microbial Diversity in the Reactor}

Overall 12,604 bacterial and 13,839 archaeal nonchimeric, good-quality sequences were retrieved from the reactor, representing 896 bacterial operational taxonomic units (OTU)-97\% and 148 archaeal OTU-97\%. Rarefication curves showed that the bacterial and archaeal communities were sampled sufficiently (online suppl. Fig. S1; see www.karger.com/doi/10.1159/000479108 for all online suppl. material) and the sampling complied with Good's coverage ranging from 97 to $100 \%$. In general, the largest bacterial diversity and bacterial species richness were found in the mixing fossa, followed by the sedimentation pond, and the lowest were detected in the digestion chamber. Archaeal diversity and species richness, however, were similar for the different points sampled in the reactor. Diversity and species richness were higher for bacteria than for Archaea. The number of bacterial OTU97\% was 3-7 times larger than that for Archaea. Kim et al. [2015] found that the number of bacterial 16S RNA gene copies based on qPCR was 10 -fold higher than that of Archaea in anaerobic digesters treating different organic wastes, while Lee et al. [2016] reported a 100-fold higher number in a full-scale thermophilic anaerobic digester. The highest bacterial and archaeal diversity in terms of heterogeneity was found in the mixing fossa and the lowest in the digester chamber. It is likely that the diversity in the digestion reactor decreased as particular microbial guilds were favored by the digestion conditions.

\section{Microbial Community in the Mixing Fossa: Entrance} to the Digester

In the mixing fossa, where the pig waste is collected before being transferred to the digestion reactor, Fir- micutes $(61.1 \pm 3.3 \%)$ were the dominant bacterial phylum, followed by Proteobacteria $(21.1 \pm 1.3 \%)$ and Bacteroidetes $(14.8 \% \pm 2.5)$, while the relative abundance of 14 phyla was $<1 \%$ (Fig. 1). Phylotypes belonging to Clostridia class $(38.2 \pm 4.6 \%)$ dominated Firmicutes, Gammaproteobacteria $(18.9 \pm 0.5 \%)$ dominated Proteobacteria, and Bacteroidia (14.5 $\pm 2.8 \%)$ dominated Bacteroidetes. Bacterial orders, and especially Bacteroidales and Pseudomonadales, were dominated by a limited number of genera. Bacteroidales $(14.5 \pm 1.5 \%)$ were dominated by the genus Prevotella (10.6 $\pm 2.7 \%)$, and half of the phylotypes belonging to Pseudomonadales $(14.3 \pm 1.9 \%)$ belonged to the genus Acinetobacter $(7.2 \pm 2.4 \%)$. As could be expected, the bacterial community in the mixing fossa resembled bacteria found in animal feces. Many phylotypes belonging to Firmicutes possess enzymes that ferment plant cell wall components [Ziemer, 2013], and members of the Ruminococcaceae are known to produce short-chain fatty acids, which might promote gut health [Bearson et al., 2013]. Two bacterial families, i.e., Prevotellaceae (Bacteroidales) and Moraxellaceae (Pseudomonadales), had a high relative abundance in the mixing fossa. Prevotellaceae is one of the most prevalent families in the swine gastrointestinal tract [Bearson et al., 2013], and strains belonging to Moraxellaceae are commensals or cause opportunistic infections [Pettersson et al., 1998]. As such, their high relative abundance in organic waste is easily understood. Strains of the genus Prevotella have been found in animal (pig, dog, and cat) and human feces [Haugland et al., 2010]. Strains belonging to the genus Acinetobacter are opportunistic human and animal pathogens [Hong et al., 2013].

Most of the sequences retrieved from the digester belonged to Euryarchaeota ( $99.8 \pm 0.1 \%$ ) (mostly Methanomicrobia; $99.0 \pm 1.3 \%$ ), while the rest belonged to Crenarchaeota $(0.2 \pm 0.1 \%)$ and Thermoplasmata $(0.3 \pm 0.1 \%)$ (online suppl. Table S2). Only $0.03 \%$ of the retrieved se-
308

J Mol Microbiol Biotechnol 2017;27:306-317 DOI: $10.1159 / 000479108$
Pampillón-González/Ortiz-Cornejo/ Luna-Guido/Dendooven/Navarro-Noya 
Fig. 1. Schematic representation of the anaerobic digester indicating the 3 sampling points, i.e., the mixing fossa (entrance), the digestion chamber (middle), and the sedimentation pond (exit), and the most abundant bacterial and archaeal groups at each of these sampling points.

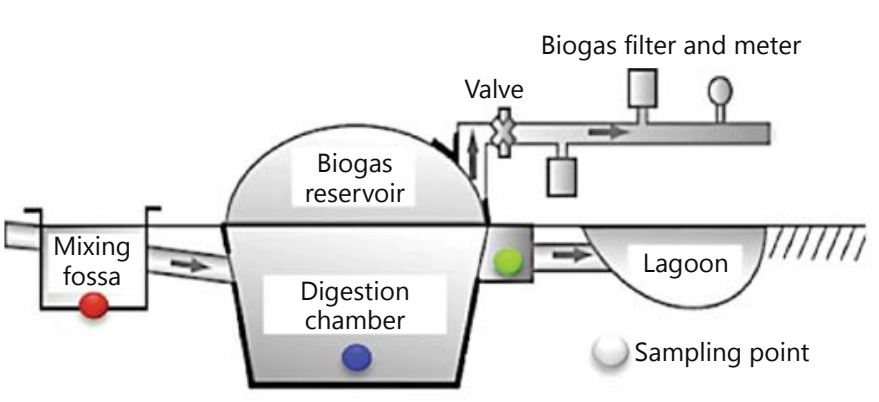

Bacterial phyla $\square$ Sedimentation pond $\square$ Digestion chamber $\square$ Mixing fossa

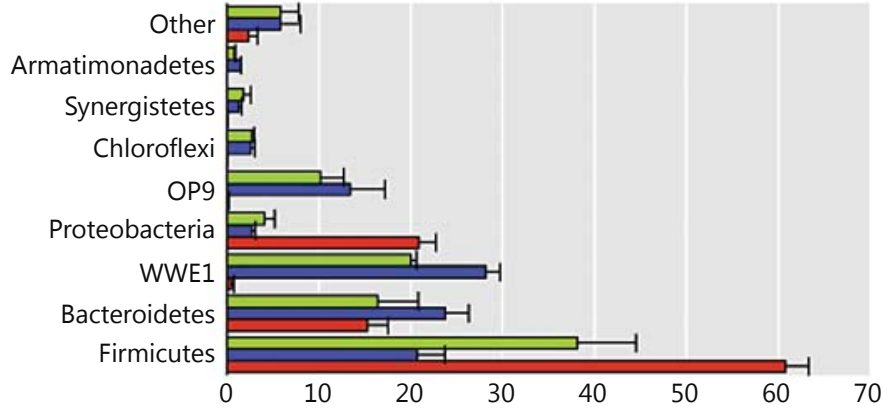

Bacterial lower level taxa

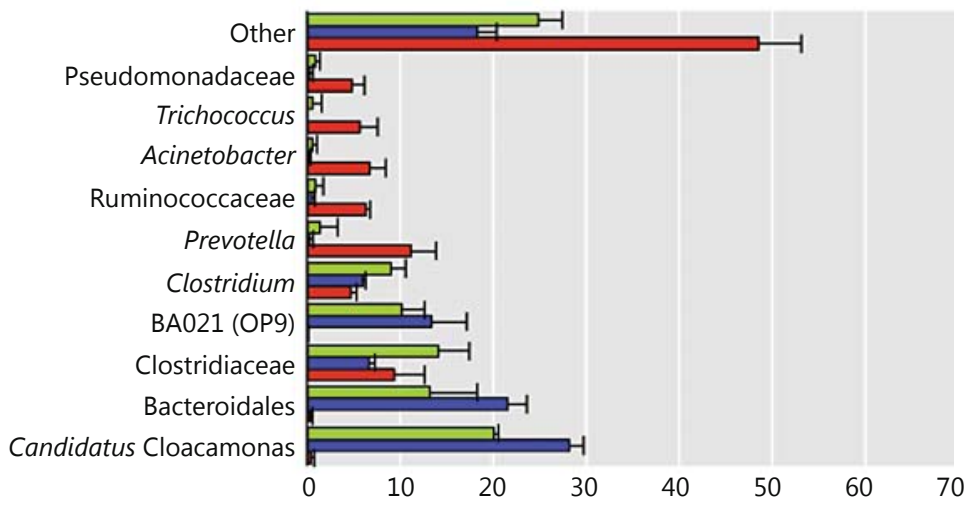

Archaeal lower level taxa

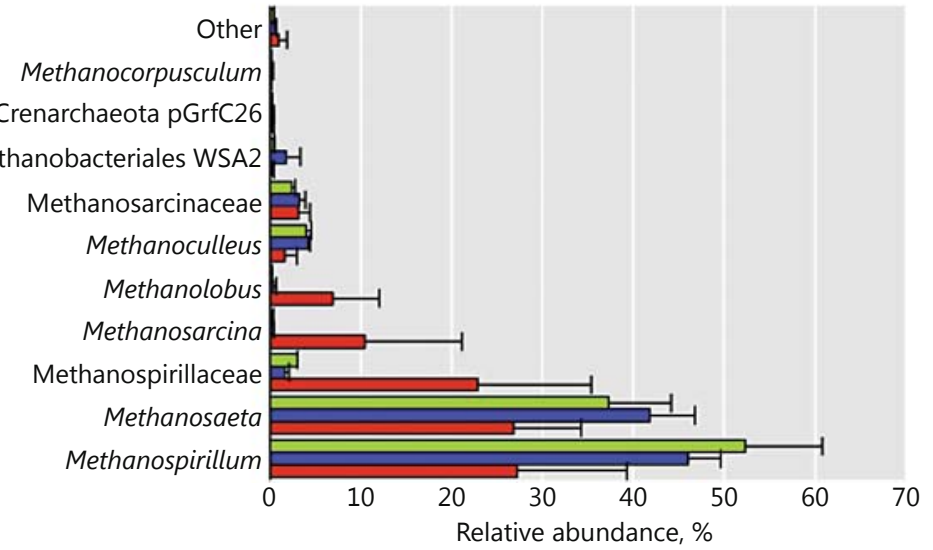

Microbial Communities in a Biogas Reactor
J Mol Microbiol Biotechnol 2017;27:306-317 DOI: $10.1159 / 000479108$ 
quences could not be assigned to an archaeal group. Methanospirillum and Methanosaeta dominated the archaeal community in the mixing fossa. The archaeal community in the mixing fossa was different from that reported for swine feces as Methanobrevibacter spp. is normally dominant [Ufnar et al., 2007]. Some phylotypes were affiliated with Crenarchaeota and Thermoplasmata. Thermoplasmata belong to the Euryarchaeota and have been detected in bovine rumen. Their methanogenic lifestyle was confirmed as they have distinct methyl-coenzyme M reductase genes [Poulsen et al., 2013]. The methanogenesis pathways of the dominant Archaea at the entrance of the reactor were acetoclastic (Methanosarcina, Methanolobus, and Methanosaeta) and hydrogenothrophic (Methanospirillum and Methanospirilaceae). Different organic sources can be used for methane production. The microbial community found in the reactor fed with pig manure in this study contained microorganisms with biochemical capacities involved in the 4 phases of methane production.

\section{Microbial Community in the Digestion Chamber}

In the anaerobic digester reactor, the bacterial population was dominated by Waste Water of Evry 1 (WWE1) $(28.6 \pm 1.9 \%)$, followed by Bacteroidetes $(23.6 \pm 3.0 \%)$, Firmicutes $(20.1 \pm 4.1 \%)$, and OP9 (13.8 $\pm 4.2 \%)$ (Fig. 1). Phylotypes belonging to Cloacamonae $(28.6 \pm 1.9 \%)$ dominated WWE1, and Bacteroidia $(23.6 \pm 3.0 \%)$ dominated Bacteroidetes, Clostridia (19.1 $\pm 3.0 \%)$ dominated Firmicutes, and JS1 $(13.8 \pm 4.2 \%)$ dominated OP9. A different bacterial community was selected in the digester chamber compared to the mixing fossa. The relative abundance of the 2 dominant phyla in the mixing fossa decreased sharply. Lactobacillales $(18.4 \pm 3.8 \%)$ and Pseudomonadales $(14.3 \pm 1.9 \%)$, so dominant in the mixing fossa, were nearly absent from the digestion chamber. The relative abundance of Clostridiales was halved as phylotypes belonging to the families Lachnospiraceae $(6.1 \pm 1.3 \%)$, Ruminococcaceae $(8.1 \pm 0.8 \%)$, and Veillonellaceae $(3.9 \pm 1.2 \%)$ nearly disappeared $(<1 \%)$ from the digester chamber. Lachnospiraceae, Ruminococcaceae, and Veillonellaceae are symbiotic gut bacteria, so once they leave this specific environment their relative abundance declines as the composition of the organic material and conditions change [Gevers et al., 2014].

Although the relative abundance of Bacteroidales increased from $14.5 \pm 2.8 \%$ in the mixing fossa to $23.6 \pm$ $3.0 \%$ in the digestion chamber, there was a clear change in the phylotypes that dominated this order. The relative abundance of the genus Prevotella dropped from to 10.6 \pm 2.7 to $0.2 \pm 0.4 \%$, but $21.4 \pm 2.7 \%$ of the phylotypes be- longing to Bacteroidales remained unclassified in the digester chamber. The OP9 and WWE1 phyla were dominated by 1 bacterial group. OP9 was dominated exclusively by BA021 $(13.8 \pm 4.2 \%)$ and WWE1 by the genus Candidatus Cloacamonas $(28.6 \pm 1.9 \%)$ (online suppl. Fig. S2). Most species belonging to these 2 phyla have not been cultivated yet, but they were most likely involved in the anaerobic degradation of organic material. Candidatus Cloacamonas probably participated in the fermentation and acidogenesis process. This genus has been found in anaerobic digesters [Chouari et al., 2005]. Pelletier et al. [2008], after an in silico proteome analysis, stated that "Candidatus Cloacamonas acidaminovorans" might derive most of its carbon and energy from the fermentation of amino acids and is probably a syntrophic bacterium. Additionally, Limam et al. [2014], using stable isotope probing, stated that members of WWE1 participate in the extracellular cellulose hydrolysis process and/or in the uptake of fermentation products. OP9 has been found in thermal bioreactors and digesters, petroleum reservoirs, and geothermal springs and most likely participate in acidogenesis [Dodsworth et al., 2013]. Through metabolic reconstruction from the core genome obtained from single-cell and metagenomic sequencing, Dodsworth et al. [2013] stated that this yet uncultured bacterial lineage (i.e., OP9) had "an anaerobic lifestyle based on sugar fermentation by Embden-Meyerhof glycolysis with production of hydrogen, acetate and ethanol."

Of the methanogens that entered the reactor from the pig manure, the acetoclastic Methanosaeta and the hydrogenothrophic Methanoculleus and Methanospirillum were favored in the digestion chamber. Acetoclastic methanogens accounted for $42 \%$ of the Archaea in the digestion chamber, while hydrogenotrophic methanogens for 52\%. Sundberg et al. [2013] studied 21 full-scale biogas digesters with different types of wastes and generalized that digesters with sewage sludge contained mainly acetoclastic methanogens, while hydrogenotrophic methanogens were found mainly when other wastes were used. Kim et al. [2015] studied batch digesters treating different organic sources, e.g., sewage sludge, food waste, and septage, and found a similar proportion of Methanosarcinales (acetoclastic) and Methanomicrobiales (hydrogenotrophic) in digesters with sewage sludge. In this work an almost equal proportion of acetoclastic and hydrogenotrophic methanogenic Archaea was found, indicating that methane production was probably achieved almost equally through both pathways. Different factors, however, affect methane production through the acetoclastic and hydrogenotrophic pathways. First, the rela-
310

J Mol Microbiol Biotechnol 2017;27:306-317 DOI: $10.1159 / 000479108$
Pampillón-González/Ortiz-Cornejo/ Luna-Guido/Dendooven/Navarro-Noya 


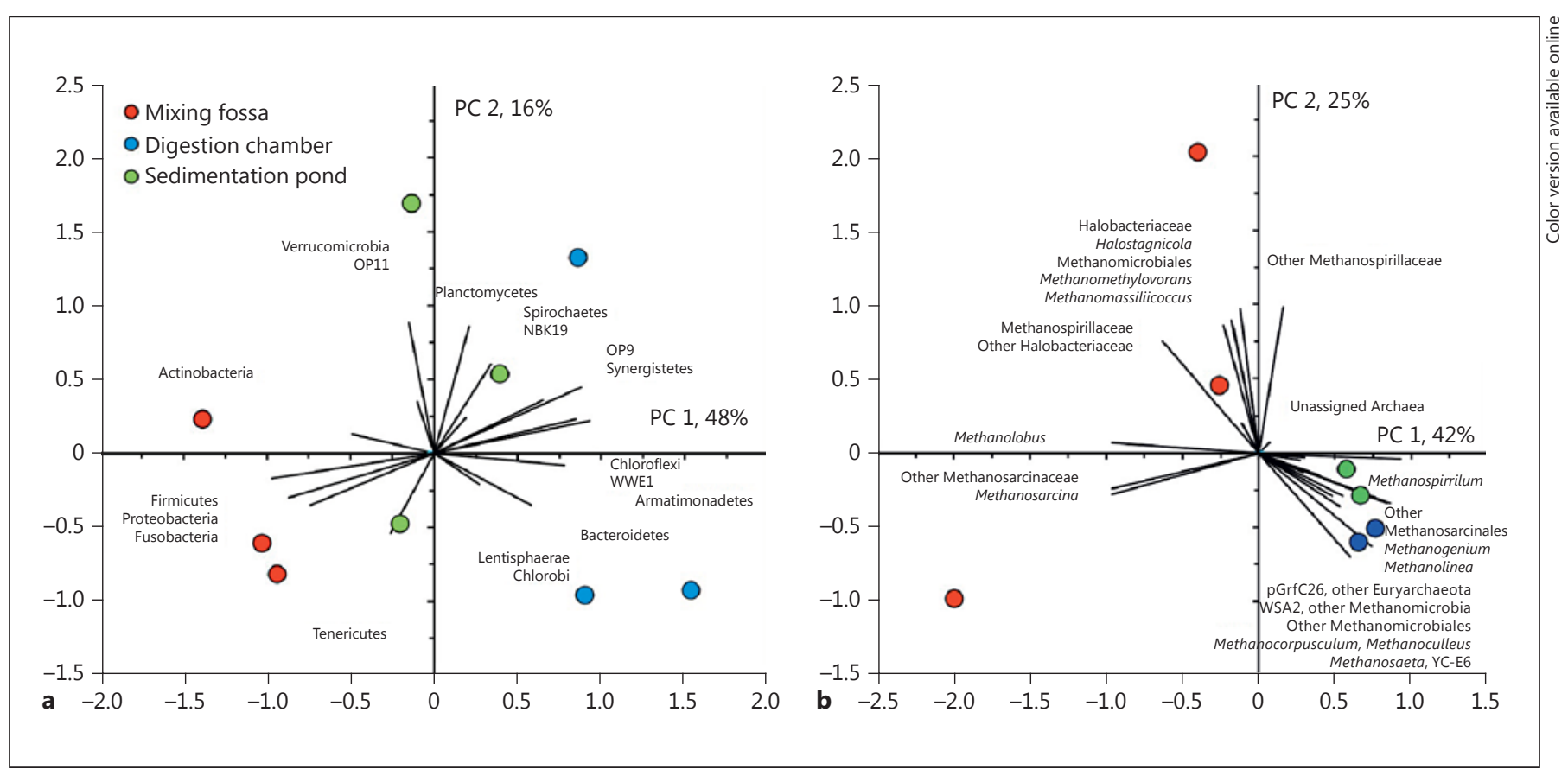

Fig. 2. Principal component analysis considering the relative abundance of the different bacterial phyla (a) and archaeal genera (b) found in the mixing fossa, the digestion chamber, and the sedimentation pond.

tive abundance of the different methanogens is important. Karakashev et al. [2006] observed that when Methanosaetaceae were absent the dominant methanogenic pathway was hydrogenotrophic. Methanosaeta was detected so the 2 pathways probably contributed to $\mathrm{CH}_{4}$ production. Second, the composition of the organic material affects the relative importance of the 2 pathways. When the organic material consist mostly of polysaccharides, theoretical models predict that acetoclastic methanogenesis accounts for $>67 \%$ of the $\mathrm{CH}_{4}$ production and hydrogenotrophic methanogenesis accounts for $<33 \%$ [Conrad, 1999].

\section{Microbial Community in the Sedimentation Pond: \\ Exit of the Digester}

The bacterial community in the sedimentation pond was dominated by bacterial groups that were also abundant in the digestion chamber, e.g., BA021 (10.9 $\pm 4.2 \%)$, Candidatus Cloacamonas (19.3 $\pm 0.9 \%)$, and unclassified Bacteroidales $(13.2 \pm 4.6 \%)$. Although the relative abundance of Clostridiales $(34.8 \pm 3.1 \%)$ was similar in the digester and in the mixing fossa $(38.2 \pm 3.1 \%)$, the bacterial groups that dominated them were distinct. The relative abundance of Clostridiaceae was $>2$ times higher in the sedimentation pond $(28.0 \pm 5.5 \%)$ than in the anaero-

Microbial Communities in a Biogas Reactor bic digester $(12.1 \pm 2.5 \%)$. Clostridiaceae were dominated by phylotypes belonging to the genera Clostridium and Proteiniclasticum. The archaeal groups in the sedimentation pond were similar to those found in the digestion chamber and no significant difference was found in their phylogenetic composition and taxonomic structure (Fig. 2, 3).

\section{Changes in the Microbial Community Structure along} the Sampling Points

Taxonomic distribution (Fig. 2) and phylogenetic composition (Fig. 3) information revealed that the bacterial and especially the archaeal communities remained rather stable in the anaerobic reactor, even when replicates were taken with 50 days in between, while variations were larger in the mixing fossa. These analyses also confirm that bacterial and archaeal communities were different between the sampling points. Considering the different bacteria phyla the mixing fossa, for instance, was characterized by a negative PC1 (a high relative abundance of Actinobacteria, Firmicutes, Fusobacteria, and Proteobacteria), while the digester reactor was characterized by a positive PC1 (a high relative abundance of Armatimonadetes, Bacteroidetes, Chloroflexi, OP9, Synergistetes, and WWE1) (Fig. 2a). The archaeal commu-

J Mol Microbiol Biotechnol 2017;27:306-317 DOI: $10.1159 / 000479108$ 


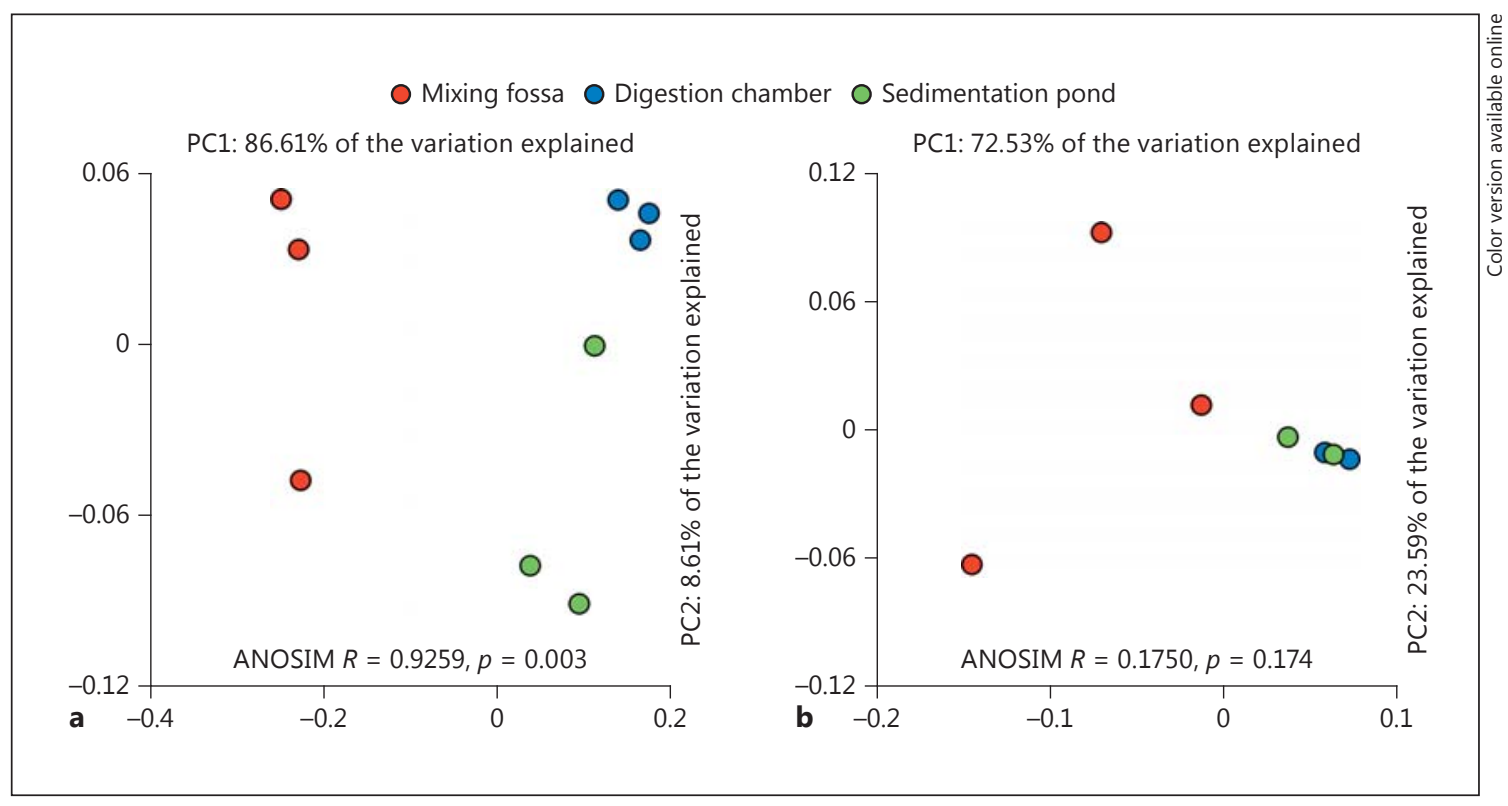

Fig. 3. Principal coordinate analysis of the weighted UniFrac distances of bacterial (a) and archaeal (b) communities. Analysis of similarities (ANOSIM) was used to compare the bacterial and archaeal composition among the 3 sampling points, i.e., the mixing fossa (entrance), the digestion chamber (middle), and the sedimentation pond (exit).

nity structure in the mixing fossa was clearly different from those of the anaerobic digester reactor and the sedimentation pond (Fig. 2b). At the OTU-97\% level and considering the phylogenetic affiliation, the bacterial communities were separated clearly and they were significantly different $(p=0.003$, Fig. 3a). The bacterial community of the mixing fossa differed mostly from that in the digester, while the bacterial community of the sedimentation pond was in between that of the mixing fossa and the digester. The archaeal communities showed the same tendency (Fig. 3b). However, the archaeal communities in the digester and in the sedimentation pond remained close.

As mentioned before, anaerobic digestion is a delicate and equilibrated interaction of different guilds of microorganisms. The success of biogas production depends on the maintenance of this equilibrium. In this study, we observed that resilient microbial populations might maintain this balance. Werner et al. [2011] observed in 9 different types of methanogenic bioreactors stable bacterial communities in terms of taxonomic profiles and phylogenetic structure that were resilient to disturbances. They suggested that resilience, rather than dynamic competition, played an important role in maintaining the necessary syntrophic populations.
Effect of the Physicochemical Parameters on the Microbial Communities Composition

The canonical correlation analysis (CCA) of the bacterial communities separated the mixing fossa from the digester and the sedimentation pond (Fig. 4a). The large organic carbon content in the mixing fossa was positively correlated with Actinobacteria, Firmicutes (mostly Lactobacillales, Bacilli), and Proteobacteria (mostly Pseudomonadales, Gammaproteobacteria).

The composition of the archaeal communities was better explained by the physicochemical parameters of the sampling points (Fig. 4b). The sedimentation pond was separated clearly from the anaerobic digester reactor while the mixing fossa was found in between. The sedimentation pond was characterized by a higher $\mathrm{pH}$ than those of the mixing fossa and the anaerobic digester. One sample from the sedimentation pond had a higher relative abundance for Methanolinea and Methanoculleus, i.e., a high negative CCA1, compared to the samples from the sedimentation pond and the anaerobic digester, and the second sample had a higher relative abundance of Methanospirillum, i.e., a high positive CCA1.
Pampillón-González/Ortiz-Cornejo/ Luna-Guido/Dendooven/Navarro-Noya 


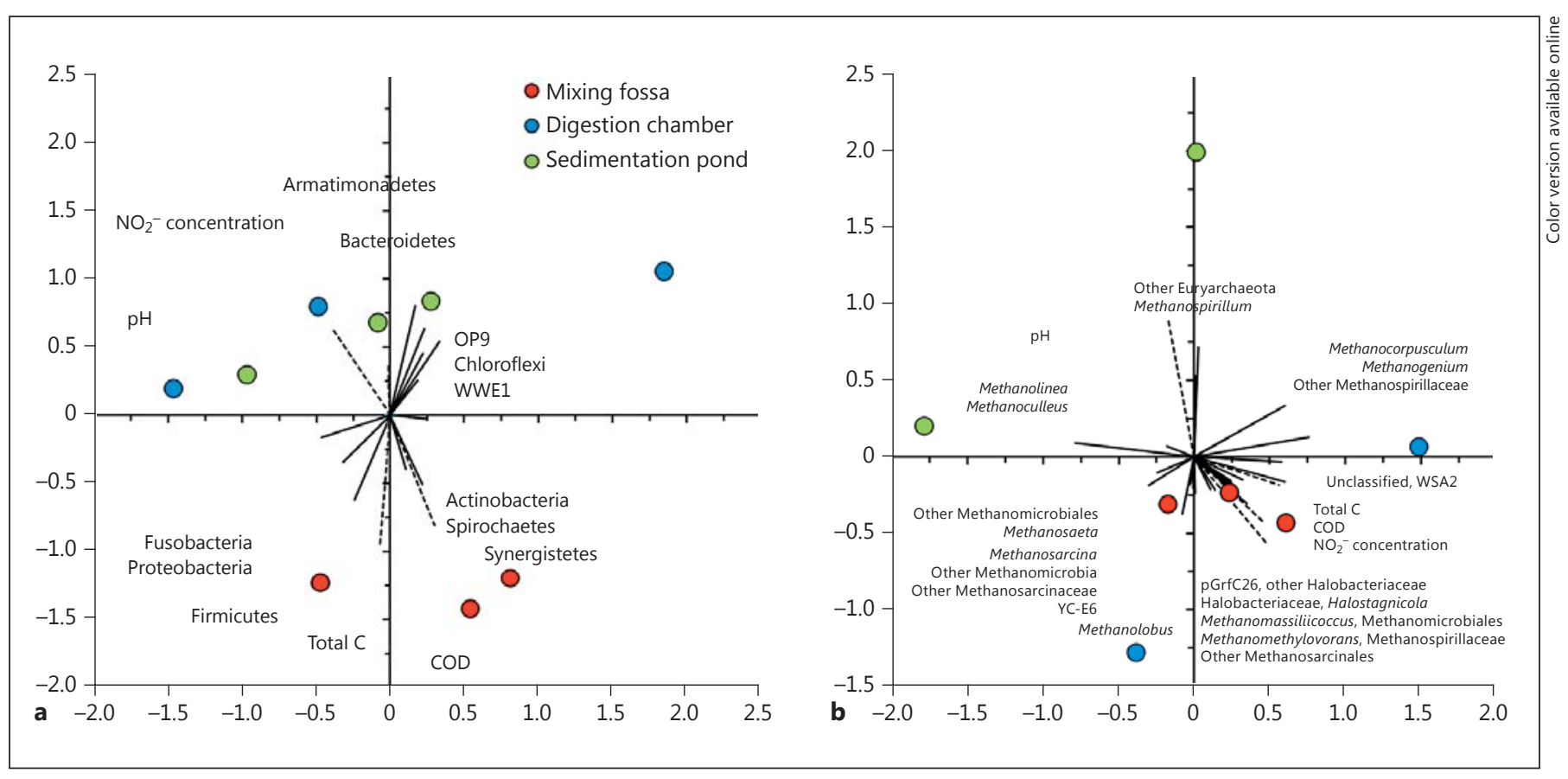

Fig. 4. Canonical correlation analysis considering the relative abundance of the different bacterial phyla (a) and archaeal genera (b) and soil characteristics that were significantly different among the sampling points, i.e., $\mathrm{pH}$, organic $\mathrm{C}$ content, nitrite $\left(\mathrm{NO}_{2}^{-}\right)$concentration, and chemical oxygen demand (COD).

\section{KEGG Ortholog Function Prediction}

A metagenome prediction was made considering the bacterial and archaeal communities. The most abundant metabolic functions in the anaerobic reactor were related to central metabolisms and organic matter degradation (Fig. 5a). Metagenomic analysis of a production scale biogas plant fed with renewable primary products found a significant amount of genes involved in sugar and amino acid metabolism [Schlüter et al., 2008]. Stolze et al. [2015] found that key functions for organic material decomposition and methane synthesis of biogas reactors under wet and dry fermentation were very similar. Surprisingly, different metabolic functions associated with degradation of xenobiotic compounds, i.e., chloroalkane and chloroalkene, ethylbenzene, and fluorobenzoate, were significantly different between the mixing fossa and the anaerobic digester (Fig. 5b). It has been suggested that aromatic compounds are intermediate degradation products of organic material to $\mathrm{CH}_{4}$ [Grbic-Galic, 1986; Kotsyurbenko et al., 2004]. Kotsyurbenko et al. [2004] hypothesized that they may be released from lignin, humic acids, or aromatic amino acids. Degradation of aromatic compounds might result in substantial production of $\mathrm{H}_{2}$, which eventually increases the relative contribution of hydrogeno- trophic methanogenesis. Here, though it was derived from predicted observations, we found the same phenomenon.

\section{Conclusions}

The number of bacterial OTU-97\% was 3-7 times larger than that of the archaeal ones. The waste that entered the digester was dominated mostly by bacteria found in the feces of pigs, e.g., Clostridiaceae, Lachnospiraceae, Veillonellaceae, and Ruminococcaceae. The methanogenesic pathways of the dominant Archaea at the entrance of the reactor were acetoclastic (Methanosarcina, Methanolobus, and Methanosaeta) and hydrogenothrophic (Methanospirillum and Methanospirillaceae). The anaerobic digester was dominated by bacteria with an anaerobic lifestyle based on sugar fermentation (OP9) or syntrophic bacteria, such as Candidatus Cloacamonas. They derive most of their carbon and energy from the fermentation of amino acids and also participate in the extracellular cellulose hydrolysis process and/or in the uptake of fermentation products. The methanogens selected in the digestion chamber were the acetoclastic Methanosaeta and the 


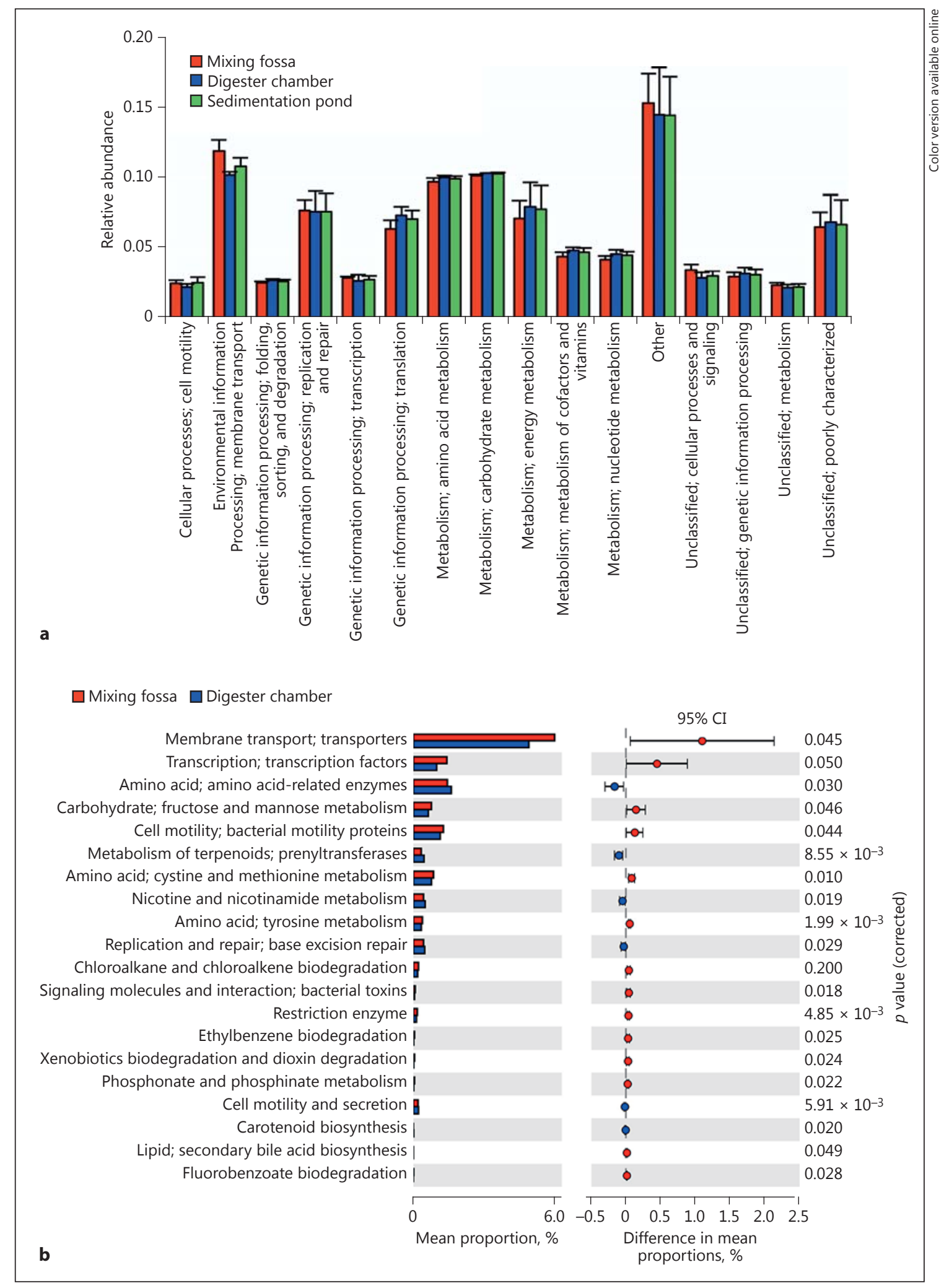

Fig. 5. KEGG ortholog classification of the predicted functions of the microbial communities found in the mixing fossa, the digestion chamber, and the sedimentation pond: most abundant functions (a) and functions with different abundances (b) in the mixing fossa and the anaerobic chamber.

Pampillón-González/Ortiz-Cornejo/ Luna-Guido/Dendooven/Navarro-Noya 
hydrogenothrophic Methanoculleus and Methanospirillum. Acetoclastic methanogens accounted for $42 \%$ of the phylotypes retrieved, while hydrogenotrophic methanogens accounted for $52 \%$. The waste that left the digester was dominated by bacterial and archaeal groups similar to those that dominated in the digestion chamber. Functions associated with degradation of xenobiotic compounds, i.e., chloroalkane and chloroalkene, ethylbenzene, and fluorobenzoate, were different significantly between the mixing fossa and the anaerobic digester.

\section{Experimental Procedures}

\section{Anaerobic Digestion Lagoon Type System and Sampling}

Swine wastewater was sampled from an anaerobic digestion reactor (lagoon type) installed in a pig farm (Granja Porcicola Topoyanes (State of Puebla, Mexico) (online suppl. Fig. S3). The pig farm is located in Huejotzingo (2,230 $\mathrm{m}$ above sea level, $19^{\circ} 07^{\prime} \mathrm{N} 98^{\circ} 22^{\prime}$ W), $85 \mathrm{~km}$ southeast of Mexico City. The climate is temperate, with dry winters $(\mathrm{Cwb})$, a mean annual temperature of $10^{\circ} \mathrm{C}$, and a precipitation of $600 \mathrm{~mm}$. The anaerobic digestion reactor used for biogas production was located beside the stables at a farm with a total pig population of 7,000 animals. The mean biogas yield of the anaerobic digestion reactor was $409.22 \mathrm{~m}^{3} /$ day (range 318.6-543.9 $\mathrm{m}^{3} /$ day), with $67 \% \mathrm{CH}_{4}, 32 \% \mathrm{CO}_{2}, 0.3 \% \mathrm{O}_{2}$, and $1,732 \mathrm{ppm}$ of $\mathrm{H}_{2} \mathrm{~S}$. Biogas yields were measured with a portable gas analyzer (Biogas 5000; Geotech, UK). The collection of biogas was continuous. The produced gas left the anaerobic digestion reactor through flexible neoprene tubing connected to a flow meter and filters of zeolite and active carbon, where water and $\mathrm{H}_{2} \mathrm{~S}$ is removed from the gas. Biogas free of $\mathrm{H}_{2} \mathrm{~S}$ is directly injected to the generator.

The anaerobic digestion reactor was sampled at 3 different locations, i.e., the mixing fossa, the anaerobic digester, and the exit of the digester (considered the sedimentation pond) and replicate samples were taken with 50 days in between and the archaeal and bacterial communities, and chemical properties characterized.

The mixing fossa, though not strictly part of the anaerobic reactor, was considered important to study as it determined the quality of the slurry before it was added to the reactor. The animal waste (mostly feces) derived from the pig units was mixed with water in a relation of 1:6-1:10. The mixing fossa was covered and agitated, but not continuously. The feces were passed through a canal and accumulated in the fossa. The slurry was retained for approximately 50 days.

The feces mixed with water (influent) were pumped from the mixing fossa to the digester reactor, which is a covered lagoon of $2,700 \mathrm{~m}^{3}$ (online suppl. Fig. S3). The rectangular pond with slopes of $60^{\circ}$ and an average depth of $6 \mathrm{~m}$ was covered with a $1.5-\mathrm{mm}$ thick high-density polyethylene. The content in the covered lagoon was mixed with a centrifugal chopper-agitator pump. Anaerobic digestion took place in the covered lagoon for approximately 55 days. The average biogas production was $322.25 \mathrm{~m}^{3} /$ day at sampling. The temperature in the anaerobic reactor ranged from 35 to $55^{\circ} \mathrm{C}$ and the processes are thus mesophilic-thermophilic. The temperature in the anaerobic reactor when the samples were taken, i.e., during the mesophilic part of the process, was $35^{\circ} \mathrm{C}$. The covered lagoon was sampled in the middle by means of an extrac- tion pump fitted with a 4-m tube. Samples were taken at a depth of between 2 and $3 \mathrm{~m}$. A third location was sampled from the exit tube of the digester reactor, i.e., from the first sedimentation pond.

A 1-1 waste sample was taken at the 3 different locations. Each sample was added to a 1,500-mL glass bottle. The samples were put on dry ice and taken to the laboratory for chemical characterization and extraction of DNA. The $\mathrm{pH}$ and electrolytic conductivity (EC) were determined at the different sampling points using a multiparametric probe (556 MPS; YSI, USA).

\section{Chemical and Microbiological Characterization}

Nitrite $\left(\mathrm{NO}_{2}^{-}\right)$, nitrate $\left(\mathrm{NO}_{3}{ }^{-}\right)$, and ammonium $\left(\mathrm{NH}_{4}{ }^{+}\right)$in the samples were quantified colorimetrically on a San Plus segmented flow analyzer (SKALAR; Breda, The Netherlands). The chemical oxygen demand was determined according to the American Public Health Association [1998], whereas total C and inorganic C were measured using a total carbon analyzer (Shimadzu- $\mathrm{V}_{\mathrm{CSN}}$ module; Shimadzu, USA). Total N was determined by the Kjeldahl method. Total and fecal coliforms and Salmonella were determined using a serial dilution on a selective medium technique and the colonies were identified by form and color [Appendix G in United States Environmental Protection Agency, 1999].

DNA Extraction and PCR Amplification of $16 S$ rRNA Genes

A 50-ml aliquot of each sample was centrifuged at 8,000 rpm for $15 \mathrm{~min}$ to recover and concentrate the suspended microbial cells. The pellet obtained was extracted for DNA as described previously [Navarro-Noya et al., 2013b].

The V1-V3 region (about $550 \mathrm{bp}$ ) of the archaeal and bacterial $16 \mathrm{~S}$ rRNA gene was amplified and pyrosequenced subsequently. The DNA samples were amplified using the set of archaeal primers 25F 5'-CYG GTT GAT CCT GCC RG-3' [Dojka et al., 1998] and A571R 5'-GCT ACG GNY SCT TTA RGC-3' [Baker et al., 2003] and bacterial primers 8 -F ( $5^{\prime}$-AGA GTT TGA TCI TGG CTC A-3') and 556-R (5'-TGC CAG IAG CIG CGG TAA-3') [Navarro-Noya et al., 2013a]. Each ribosomal primer set was flanked by a 454 adapter sequence and a 10-bp barcode between the 454 adapter and the forward primer for sample identification of the mixed amplicon libraries. The PCR protocol was followed as previously described by Navarro-Noya et al. [2013b]. The product of 5 reactions of each metagenomic DNA sample was pooled to minimize the PCR bias so that one single library was formed. All pyrosequencing libraries were purified using a DNA Clean \& Concentrator purification kit as recommended by the manufacturer (Zimo Research, Irvine, CA, USA) and quantified using a PicoGreen ${ }^{\circledR}$ dsDNA assay (Invitrogen, Carlsbad, USA) and a NanoDrop ${ }^{\mathrm{TM}} 3300$ Fluroespectrometer (Thermo Scientific). Sequencing was done by Macrogen Inc. (DNA Sequencing Service, Seoul, Korea) using a Roche 454 GS-FLX Titanium System pyrosequencer (Roche, Mannheim, Germany).

\section{Processing of the Sequences}

The QIIME version 1.8.0 software pipeline was used to analyze the pyrosequencing data [Caporaso et al., 2010b]. Poor quality reads, i.e., quality scores $<25$, containing homopolymers $>6$, length $<200 \mathrm{nt}$, and containing errors in primers and barcodes, were eliminated. OTU were clustered at a $97 \%$ similarity level with the UCLUST algorithm. Chimeras were detected and removed using Chimera Slayer. Sequence alignments were done against the Greengenes core set with PyNAST using representative sequences of each OTU and filtered at a threshold of 75\% [Caporaso et al., 
2010a]. Taxonomic assignations were done with the RDP-naive Bayesian at $80 \%$ confidence.

\section{Metagenome Prediction}

The metagenome analysis was done with PICRUSt version 1.0.0 [Langille et al. 2013]. First, an OTU table clustered at 95\% similarity was generated using the closed-reference strategy within QIIME, and Greengenes reference database version 13.5 was used to assign taxonomic groups [McDonald et al., 2012]. The OTU tables with the bacterial and archaeal data were merged and normalized to correct the number of multiple $16 \mathrm{~S}$ rRNA gene copies using Greengenes reference database version 13.5. Finally, the KEGG Orthologs functions of the metagenome were predicted using an ancestral state reconstruction algorithm.

\section{Statistical Analysis}

Statistical analysis was done with the relative abundance of the different bacterial and archaeal groups and the taxonomy distribution of OTU matrices using R software version 2.15.1 (http:// www.r-project.org/). Significant differences in the relative abundance of the archaeal and bacterial groups as a result of location in the digester (mixing the fossa or the entrance to the digester, in the middle of the digester reactor and at the exit of the digester or the sedimentation pond) were determined via analysis of variance (ANOVA) and based on the least significant difference using the general linear model procedure (PROC GLM) [SAS Institute, 1989]. PCA was used to compare the relative abundance of the different archaeal and bacterial groups of the different locations in the digester using PROC FACTOR [SAS Institute, 1989]. UniFrac distance matrices, which incorporate phylogenetic correction, were generated to compare the microbial communities at the OTU-97\% level. A canonical correlation analysis was used to study the rela- tionship between the abundance of the different archaeal and bacterial groups and the swine waste characteristics. CCA was done using PROC CANCORR of the SAS statistical package [SAS Institute, 1989]. ANOVA and post hoc analysis of the predicted KEGG ortholog functions were done in STAMP v2.1.3 [Parks et al., 2014].

\section{Data Archiving}

Raw sequences were submitted as a sequence read archive to the NCBI under BioProject accession number PRJNA329007.

\section{Acknowledgements}

This research was funded by Cinvestav (Mexico) and the project Infraestructura 205945 from the Consejo Nacional de Ciencia y Tecnología (CONACyT, Mexico). Y.E.N.-N. received a postdoctoral grant from ABACUS - Consejo Nacional de Ciencia y Tecnología (CONACyT). L.P.-G. received grant aid from CONACyT. We thank Granja Porcicola Topoyanes for providing the anaerobic digested sludge (Puebla, Mexico). Lourdes Moreno Rivera assisted with the microbiological characterization of the digestate. The authors thank ABACUS (CONACyT) for providing time on their computer to denoise the DNA sequences.

\section{Disclosure Statement}

The authors declare that there is no conflict of interests regarding the publication of this paper.

\section{References}

Ali Shah F, Mahmood Q, Maroof Shah M, Pervez A, Ahmad Asad S: Microbial ecology of anaerobic digesters: the key players of anaerobiosis. Sci World J 2014, DOI: 10.1155/2014/ 183752.

American Public Health Association: Standard methods for the examination of water and wastewater. Washington, APHA/AWWA/ WEF, 1998.

Baker GC, Smith JJ, Cowan DA: Review and reanalysis of domain-specific $16 \mathrm{~S}$ primers. J Microbiol Meth 2003;55:541-555.

Bearson SMD, Allen HK, Bearson BL, Looft T, Brunelle BW, Kich JD, Tuggle CK, Bayles DO, Alt D, Levine UY, Stanton TB: Profiling the gastrointestinal microbiota in response to Salmonella: low versus high Salmonella shedding in the natural porcine host. Infect Genet Evol 2013;16:330-340.

Caporaso JG, Bittinger K, Bushman FD, DeSantis TZ, Andersen GL, Knight R: PyNAST: a flexible tool for aligning sequences to a template alignment. Bioinformatics 2010a;26:266267.
Caporaso JG, Kuczynski J, Stomabaugh J, Bittinger K, Bushman FD, Costello EK, Fierer N, Pena AG, Goodrich JK, Gordon JI, Huttley GA, Kelley ST, Knights D, Koening JE, Ley $\mathrm{RE}$, Lozupone CA, McDonald D, Muegge BD, Pirrung M, Reeder J, Sevinsky JR, Turbaugh PJ, Walters WA, Widmann J, Yatsunenko T, Zaneveld J, Knight R: QIIME allows analysis of high-throughput community sequencing data. Nat Methods 2010b;7:335-336.

Chouari R, Le Paslier D, Daegelen P, Ginestet P, Weissenbach J, Sghir A: Novel predominant archaeal and bacterial groups revealed by molecular analysis of an anaerobic sludge digester. Environ Microbiol 2005;7:11041115.

Conrad R: Contribution of hydrogen to methane production and control of hydrogen concentrations in methanogenic soils and sediments. FEMS Microbiol Ecol 1999;28:193-202.

Dodsworth JA, Blainey PC, Murugapiran SK, Swingley WD, Ross CA, Tringe SG, Chain PSG, Scholz MB, Lo CC, Raymond J, Quake SR, Hedlund BP: Single-cell and metagenom- ic analyses indicate a fermentative and saccharolytic lifestyle for members of the OP9 lineage. Nat Comm 2013;4:1854.

Dojka MA, Hugenholtz P, Haack SK, Pace NR: Microbial diversity in a hydrocarbon- and chlorinated-solvent-contaminated aquifer undergoing intrinsic bioremediation. Appl Environ Microbiol 1998;64:3869-3877.

El-Mashad HM, Zeeman G, van Loon WK, Bot GP, Lettinga G: Effect of temperature and temperature fluctuation on thermophilic anaerobic digestion of cattle manure. Bioresour Technol 2004;95:191-201.

Gevers D, Kugathasan S, Denson LA, VazquezBaeza Y, Van Treuren W, Ren BY, Schwager E, Knights D, Song SJ, Yassour M, Morgan $\mathrm{XC}$, Kostic AD, Luo CW, Gonzalez A, McDonald D, Haberman Y, Walters T, Baker S, Rosh J, Stephens M, Heyman M, Markowitz J, Baldassano R, Griffiths A, Sylvester F, Mack D, Kim S, Crandall W, Hyams J, Huttenhower C, Knight R, Xavier RJ: The treatment-naive microbiome in new-onset Crohn's disease. Cell Host Microbe 2014;15:382-392.
Pampillón-González/Ortiz-Cornejo/ Luna-Guido/Dendooven/Navarro-Noya 
Grbic-Galic D: Anaerobic production and transformation of aromatic hydrocarbons and substitutes phenols by ferulic acid-degradin BESA-inhibited methanogenic consortia. FEMS Microbiol Ecol 1986;38:161-169.

Hattori S, Kamagata Y, Hanada S, Shoun H: Thermacetogenium phaeum gen. nov., sp. nov., a strictly anaerobic, thermophilic, syntrophic acetate-oxidizing bacterium. Int J Syst Evol Microbiol 2000;50:1601-1609.

Haugland RA, Varma M, Sivaganesan M, Kelty C, Peed L, Shanks OC: Evaluation of genetic markers from the $16 \mathrm{~S}$ rRNA gene $\mathrm{V} 2$ region for use in quantitative detection of selected Bacteroidales species and human fecal waste by qPCR. Syst Appl Microbiol 2010;33:348-357.

Hong PY, Yannarell AC, Dai QH, Ekizoglu M, Mackie RI: Monitoring the perturbation of soil and groundwater microbial communities due to pig production activities. Appl Environ Microbiol 2013;79:2620-2629.

Karakashev D, Batstone DJ, Trably E, Angelidaki I: Acetate oxidation is the dominant methanogenic pathway from acetate in the absence of Methanosaetaceae. Appl Environ Microbiol 2006;72:5138-5141.

Kim YM, Jang HM, Lee K, Chantrasakdakul P, Kim D, Park KY: Changes in bacterial and archaeal communities in anaerobic digesters treating different organic wastes. Chemosphere 2015;141:134-137.

Kotsyurbenko OR, Chin KJ, Glagolev MV, Stubner S, Simankova MV, Nozhevnikova AN, Conrad R: Acetoclastic and hydrogenotrophic methane production and methanogenic populations in an acidic West-Siberian peat bog. Environ Microbiol 2004;6:1159-1173.

Langille MG, Zaneveld J, Caporaso JG, McDonald D, Knights D, Reyes JA, Clemente JC, Burkepile DE, Vega Thurber RL, Knight R, Beiko RG, Huttenhower C: Predictive functional profiling of microbial communities using 16S rRNA marker gene sequences. Nat Biotechnol 2013;31:814-821.

Lee J, Han G, Shin SG, Koo T, Cho K, Kim W, Hwang S: Seasonal monitoring of bacteria and archaea in a full-scale thermophilic anaerobic digester treating food waste-recycling wastewater: correlations between microbial community characteristics and process variables. Chem Eng J 2016;300:291-299.

Limam RD, Chouari R, Mazéas L, Wu TD, Li T, Grossin-Debattista J, Guerquin-Kern JL, Saidi M, Landoulsi A, Sghir A, Bouchez T: Members of the uncultured bacterial candidate division WWE1 are implicated in anaerobic digestion of cellulose. Microbiol Open 2014;3:157-167.

Lorenz H, Fischer P, Schumacher B, Adler P: Current EU-27 technical potential of organic waste streams for biogas and energy production. Waste Manag 2013;33:2434-2448.

Manyi-Loh CE, Mamphweli SN, Meyer EL, Okoh AI, Makaka G, Simon M: Microbial anaerobic digestion (bio-digesters) as an approach to the decontamination of animal wastes in pol- lution control and the generation of renewable energy. Int J Environ Res Public Health 2013;10:4390-4417.

McDonald D, Price MN, Goodrich J, Nawrocki EP, DeSantis TZ, Probst A, Andersen GL, Knight R, Hugenholtz P: An improved Greengenes taxonomy with explicit ranks for ecological and evolutionary analyses of bacteria and archaea. ISME J 2012;6:610-618.

Moset V, Cerisuelo A, Ferrer P, Jimenez A, Bertolini E, Cambra-Lopez M: Microbial examination of anaerobic sludge adaptation to animal slurry. Environ Technol 2014;35:749-758.

Navarro-Noya YE, Gómez-Acata S, MontoyaCiriaco N, Rojas-Valdez A, Suárez-Arriaga MC, Valenzuela-Encinas C, Jiménez-Bueno N, Verhulst N, Govaerts B, Dendooven L: Relative impacts of tillage, residue management and crop-rotation on soil bacterial communities in a semi-arid agroecosystem. Soil Biol Biochem 2013a;65:86-95.

Navarro-Noya YE, Suárez-Arriaga MC, RojasValdes A, Montoya-Ciriaco NM, GómezAcata S, Fernández-Luqueño F, Dendooven L: Pyrosequencing analysis of the bacterial community in drinking water wells. Microb Ecol 2013b;66:19-29.

Nkoa R: Agricultural benefits and environmental risks of soil fertilization with anaerobic digestates: a review. Agron Sustain Dev 2014;34: 473-492.

Parks DH, Tyson GW, Hugenholtz P, Beiko RG: STAMP: Statistical analysis of taxonomic and functional profiles. Bioinformatics 2014;30: 3123-3124.

Pelletier E, Kreimeyer A, Bocs S, Rouy Z, Gyapay G, Chouari R, Riviere D, Ganesan A, Daegelen P, Sghir A, Cohen GN, Medigue C, Weissenbach J, Le Paslier D: "Candidatus Cloacamonas acidaminovorans": genome sequence reconstruction provides a first glimpse of a new bacterial division. J Bacteriol 2008; 190:2572-2579.

Pettersson B, Kodjo A, Ronaghi M, Uhlen M, Tonjum T: Phylogeny of the family Moraxellaceae by $16 \mathrm{~S}$ rDNA sequence analysis, with special emphasis on differentiation of Moraxella species. Int J Syst Bacteriol 1998;48:75-89.

Poulsen M, Schwab C, Jensen BB, Engberg RM, Spang A, Canibe N, Højberg O, Milinovich G, Fragner L, Schleper C, Weckwerth W, Lund P, Schramm A, Urich T: Methylotrophic methanogenic Thermoplasmata implicated in reduced methane emissions from bovine rumen. Nat Commun 2013;4:1428.

SAS Institute: Statistic Guide for Personal Computers, Version 6.04. Cary, SAS Institute, 1989.

Schlüter A, Bekel T, Diaz NN, Dondrup M, Eichenlaub R, Gartemann KH, Krahn I, Krause L, Krömeke H, Kruse O, Mussgnug JH, Neuweger H, Niehaus K, Pühler A, Runte KJ, Szczepanowski R, Tauch A, Tilker A, Viehöver P, Goesmann A: The metagenome of a biogas-producing microbial community of a production-scale biogas plant fermenter analysed by the 454-pyrosequencing technology. J Biotechnol 2008;136:77-90.

Stolze Y, Zakrzewski M, Maus I, Eikmeyer F, Jaenicke S, Rottmann N, Siebner C, Pühler A, Schlüter A: Comparative metagenomics of biogas-producing microbial communities from production-scale biogas plants operating under wet or dry fermentation conditions. Biotechnol Biofuels 2015;8:14.

Strik DPBTB, Domnanovich AM, Holubar P: A $\mathrm{pH}$-based control of ammonia in biogas during anaerobic digestion of artificial pig manure and maize silage. Process Biochem 2006; 41:1235-1238.

Sun $\mathrm{H}$, Wu S, Dong R: Monitoring volatile fatty acids and carbonate alkalinity in anaerobic digestion: titration methodologies. Chem Eng Technol 2016;39:599-610.

Sundberg C, Al-Soud WA, Larsson M, Alm E, Yekta SS, Svensson BH, Sørensen SJ, Karlsson A: 454 pyrosequencing analyses of bacterial and archaeal richness in 21 full-scale biogas digesters. FEMS Microbiol Ecol 2013;85:612-626.

Thygesen O, Sommer SG, Shin SG, Triolo JM: Residual biochemical methane potential (BMP) of concentrated digestate from full-scale biogas plants. Fuel 2014;132:44-46.

Ufnar JA, Ufnar DF, Wang SY, Ellender RD: Development of a swine-specific fecal pollution marker based on host differences in methanogen $m c r A$ genes. Appl Environ Microbiol 2007;73:5209-5217.

United States Environmental Protection Agency: Environmental regulations and technology: control of pathogens and vector attraction in sewage biosolids (including domestic septage) - under 40 CFR part 503. Cincinnati, EPA, 1999.

Walker M, Iyer K, Heaven S, Banks CJ: Ammonia removal in anaerobic digestion by biogas stripping: an evaluation of process alternatives using a first order rate model based on experimental findings. Chem Eng J 2011;178: 138-145.

Werner JJ, Knights D, Garcia ML, Scalfone NB, Smith S, Yarasheski K, Cummings TA, Beers AR, Knight R, Angenent LT: Bacterial community structures are unique and resilient in full-scale bioenergy systems. Proc Natl Acad Sci USA 2011;108:4158-4163.

Xia Y, Masse DI, McAllister TA, Kong YH, Seviour R, Beaulieu C: Identity and diversity of archaeal communities during anaerobic codigestion of chicken feathers and other animal wastes. Bioresource Technol 2014;110: 111-119.

Ziemer CJ: Broad diversity and newly cultured bacterial isolates from enrichment of pig feces on complex polysaccharides. Microb Ecol 2013;66:448-461.

Zinder SH, Koch M: Non-aceticlastic methanogenesis from acetate: acetate oxidation by a thermophilic syntrophic coculture. Arch Microbiol 1984;138:263-272.
Microbial Communities in a Biogas Reactor
J Mol Microbiol Biotechnol 2017;27:306-317 DOI: $10.1159 / 000479108$ 